\title{
LAS ENFERMERAS, LAS ENFERMAS Y LAS OTRAS MUJERES DEL HOSPITAL DE LAS CINCO LLAGAS DE SEVILLA EN EL ANTIGUO RÉGIMEN ${ }^{1}$
}

\author{
Paula Ermila Rivasplata Varillas ${ }^{2}$
}

\begin{abstract}
Las enfermeras, las enfermas y las otras mujeres del Hospital de las Cinco Llagas de Sevilla en el Antiguo Régimen

Resumen: En la Edad Moderna, el hospital podía albergar a muchas mujeres, no sólo enfermeras y enfermas, sino también criadas, esclavas, donadas, parteras, amas de cría, niñas y un variopinto enjambre de féminas pululaban sus recintos, incluso sobrinas y madres de la jerarquía masculina. Un ejemplo de ello, como señalaremos es el Hospital de la Sangre de Sevilla en el Antiguo Régimen. Este artículo describe la evolución de la enfermería femenina y los diferentes tipos de mujeres que albergaba este hospital.

Palabras clave: Mujeres, Hospital de la Sangre, Antiguo Régimen, enfermeras, enfermas, esclavas, criadas, Sevilla

The Nurses, the Patients and Other Women of the Hospital of Five Wounds of Seville in The Ancient Regime

Abstract: In the modern age, the hospital could accommodate many women, not only nurses and ill women, but maids, slaves, midwifes, children and so on. Different kinds of women were in at hospital, including nieces, mothers of the hospital male hierarchy. An example of this will be noted in the "Hospital de la Sangre de Sevilla" in the Ancient Regime. This article describes the evolution of female nursing in this hospital and the different types of women who received help and protection or abuse.

Key words: Women, Blood Hospital, Ancient Regime, nurses, sick, slaves, maids, Sevilla.
\end{abstract}

\section{Introducción}

Entre los siglos XIV al XV, época que sucedió la transición de la Baja Edad Media hacia la configuración del estado moderno renacentista estaba ya establecida la presencia de la enfermería femenina en los hospitales españoles (Hernández 1996: 98), reflejándose

\footnotetext{
${ }^{1}$ Fecha de recepción: 15/12/2014.

Fecha de aceptación: 20/12/2014.

2 Profesora Doctora en la Universidad Peruana la Unión, Lima, Perú. Doctora en Europa, el mundo mediterráneo y su difusión atlántica por la Universidad Pablo de Olavide y Doctora en Historia por la Universidad de Sevilla; $\square$ rivasplatavarillas@gmail.com.
} 
en las constituciones de dos hospitales: San Antolín de Palencia y el Hospital de Santa Cruz en Barcelona (Eseverri 1995: 28-29) ${ }^{3}$. En las constituciones de ambos hospitales se encuentran las primeras menciones de las responsabilidades del personal femenino asistencial hospitalario en España dentro del marco de la moderna organización hospitalaria que se abrió paso a finales del XIV. Pero, no significó la inauguración de la enfermería femenina institucional, sino el reconocimiento de una larga práctica secular que no podía ser obviada por más tiempo, a pesar de la misoginia que campeaba en los siglos XVI y XV (Segura 2011: 19-21; Fuentes 2010: 105-130; Beteta 2011: 46-58).

La presencia de enfermas obligó desde tiempo atrás a la división física de las enfermerías por sexos, pero las constituciones de los principales hospitales recién lo notificaron a finales del siglo XIV como Roncesvalles y San Antolín. En el siglo XV, casi todos los hospitales en donde se atendían a mujeres remarcan en sus constituciones a la mujer enfermera, como es el caso del Hospital San Juan Bautista de Guadalupe, en donde se menciona la sección femenina atendida por beatas, tal cual lo haría el hospital del Santísimo Cristo de los Dolores o "El Pozo Santo” de Sevilla en el XVII".

Durante la Edad Moderna, algunos hospitales castellanos desarrollaron eficazmente la enfermería femenina y adquirieron prestigio, lo que atrajo a mujeres de diferentes procedencias sociales, hidalgas y pobres, preferentemente solteras y viudas, a trabajar, unas por fines monetarios, otras por fines espirituales. Las jóvenes eran entregadas sin duda alguna por los padres o las instituciones de expósitos para su preparación en el oficio del cuidado para obtener un salario y una promesa de dote que le permitiese entrar al matrimonio dignamente, según los cánones de la sociedad de entonces (Rivasplata 2011). Algunas de estas mujeres podían vivir en reclusión en los hospitales, protegidas tras las

\footnotetext{
${ }^{3}$ En 1398, en las instrucciones del Hospital de San Antolín de Palencia figura la enfermera mayor, las enfermeras menores, la madre de niños, cocineras y lavanderas. En 1417, el Hospital de Santa Cruz de Barcelona incorporó en sus nuevas constituciones a las señoras de las enfermas y las señoras de los niños. ${ }^{4}$ Archivo Municipal de Sevilla (AMS). Sección 5, t.190, nº4. Fundación y regla del Santo Cristo de los Dolores y beaterio del Pozo Santo, noticias extraídas de los protocolos y papeles del mismo hospital, 1782.
} 
altas paredes, convirtiéndose en lugares seguros para mantener la honra femenina y dignificarse a sí mismas ante la sociedad.

El hospital de la Sangre de Sevilla se fundó por la noble Catalina de Rivera en 1500 para atender a enfermas curables y que no padecieran de enfermedades contagiosas (López y Torre 1995). Este hospital era considerado uno de los más importantes y grandes de España durante la Edad Moderna, creada por una familia noble y puesta bajo la responsabilidad de la Iglesia a través de un triunvirato de frailes, los priores de los monasterios de Santa María de las Cuevas, San Jerónimo de Buenavista y San Isidoro del Campo. Un hermoso edificio renacentista fue construido para albergar las numerosas instalaciones de este hospital extramuros de la ciudad de Sevilla. Este edificio fue construido con el patrimonio que donó el I Marqués de Tarifa, Adelantado de Andalucía, Alcalde Mayor de Sevilla y señor de Alcalá de los Gazules don Fadrique Enríquez de Rivera en 1539 (García 2005: 568-576). Este hospital de dos plantas tenía varios patios internos, una iglesia con cripta y capillas, sacristía, la sala capitular y oficina del administrador, un archivo, almacenes, botillería, bodega, botica, rebotica, una tahona, cuarto del secretario, del mayordomo, de los curas jubilados, de los curas activos, de los sacristanes, del boticario, del botiller, del despensero, del portero del hospital, del jardinero y del cochero. Las enfermerías estaban separadas por sexos. Un área donde estaban las enfermerías de eclesiásticos y otra de laicos. La zona femenina estaba conformada por el torno, la habitación de la madre mayor, las enfermerías femeninas (enfermedades comunes, cirugía, convalecientes, agonizantes), los lavaderos, las cocinas, la panadería, la ropería, los almacenes y el gallinero. En el fondo del hospital estaba la cochera donde estaban las carretas, las caballerías y la huerta. Este hospital ubicado en el arrabal de la Macarena tuvo un largo apogeo desde 1559 a 1648 época de bonanza económica por las donaciones testamentarias y las numerosas rentas que recibía este hospital que terminó abruptamente con la gran peste de 1649 que segó la vida de más de 60.000 sevillanos y de la mayoría de los trabajadores del hospital al convertirse en un

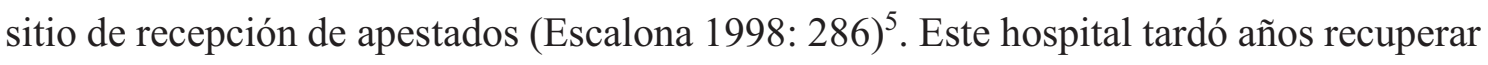

\footnotetext{
${ }^{5}$ Archivo de la Diputación Provincial de Sevilla (ADPS) Legajo 4B. Libro de actas capitulares del hospital de las Cinco Llagas (1637-1658), f. 135 r-v (1649), f. 141 r-v (1649) y f. 142 r-v (1649). A pesar de todas las precauciones que tomó el hospital, esta epidemia causó gran mortandad entre su propio personal
} 
la normalidad y la afluencia de enfermas, pero ya nunca más logró ser lo que había sido porque se produjo la crisis económica estructural en España de la que muy pocos pudieron escapar.

Ademas, este hospital atendía a los enfermos durante las pestes, funcionaba como asilo y servía de refugio durante las inundaciones (Matute 1982: 196). ${ }^{6}$ En el siglo XVIII, el hospital funcionó eficazmente, pero el declive económico era irreversible, incrementándose por la coyuntura política y bélica de comienzos del siglo XIX. Así, el periodo de 1789 a 1836 varios acontecimientos impactaron definitivamente en la labor asistencial y demás obras pías que regía la iglesia y a toda España en general, como fueron el Reformismo borbónico finisecular, la invasión francesa, la Guerra de la Independencia, la creación de la Beneficencia, la desamortización de los bienes de la Iglesia. Acontecimientos que se sumaron a las continuas inestabilidades económicas, políticas, sociales, además de la persistencia de epidemias y carestías. Ya que aunque las crisis de subsistencia del Antiguo Régimen se fueron disipando en el Nuevo Régimen, no desaparecieron del todo, así el hambruna de 1812-1813, las frecuentes catástrofes naturales (desbordes e inundaciones del Guadalquivir) y las grandes epidemias (fiebre amarilla en 1800 y 1812 y la cólera morbo en 1833) (Carmona 1997: 74) (Cuenca 1976: 26-27; Moreno 2004: 300-301). ${ }^{7}$ Finalmente, el priorato de frailes que regía este hospital desaparecería al disponer la Junta de Beneficencia la creación de una nueva institución, el Hospital Central, cuya sede sería el de las Cinco Llagas (Ramos 2003: 44).

\section{Un caso de estudio: Las mujeres del hospital de la Sangre de Sevilla}

\subsection{La madre mayor}

\footnotetext{
hospitalario, muriendo el administrador, mayordomo, secretario, curas, barbero, médico, cirujano y alguna doncella de dote. Especialmente, los eclesiásticos murieron al administrar los santos oleos.

${ }^{6}$ ADPS. Legajo 112. Libro de recibo y gasto de 1603, s/f. En gastos extraordinarios estaban consignados el pago por "limpiar y barrer la casa que quedó sucia de la gente que se recogió en ella, huyendo de la venida, seis reales"; El historiador Matute y Gaviria indica que ante la crecida del río, los habitantes del barrio de la Macarena se refugiaron en la planta superior del hospital, pues la baja estaba inundada en 1796.

${ }^{7}$ El 19 de septiembre de 1798, el Rey ordenó la enajenación de los bienes de los establecimientos benéficos.
} 
En este hospital, la única mujer considerada de rango superior equiparable a un ministro mayor, es decir, un eclesiástico del hospital (administrador, mayordomo, secretario, curas), era la madre mayor. A comienzos del siglo XVI, esta mujer llamada, también, matrona, mayordoma o ama de llaves era la responsable del buen desempeño del área femenina del hospital y de sus enfermerías. La madre mayor se ocupaba de la gestión del trabajo femenino dentro del hospital para el cumplimiento de todas las necesidades que generase el hospital en cuanto a la elaboración de comidas y del pan, confección, remiendo y lavado de la ropa, además de la atención de las enfermas (Rivasplata 2014: 529-574). La jerarquía y la obediencia al administrador y a la madre mayor eran fundamentales en el hospital. De esta manera, la madre mayor tenía su lugar establecido en la alta jerarquía del hospital en todos los actos públicos, como ministro mayor, estando ubicada después de los curas (Rivasplata 2012: 112). La madre mayor al morir recibía los honores de los ministros mencionados, es decir, la misa de cuerpo presente dado por el administrador, con presencia de los patronos durante el entierro. El hospital asumía los gastos de los ocho cirios y ocho capellanes, que se traían de afuera para los altares y la misa de cuerpo presente.

2.2. Las madres y sus doncellas

\subsubsection{Las madres}

Las mujeres que ocupaban las plazas de madres podían ser solteras o viudas, pues se exigía la completa dedicación al hospital donde vivían y trabajaban, teniendo prohibido salir del hospital sin previo permiso justificado y aprobado en junta capitular por los patronos. Hecho que muy pocas veces ocurría a excepción que estuviesen enfermas y prefiriesen ser atendidas por sus familiares. A veces se permitía el ingreso de casadas 
cuyos esposos estuviesen ausentes en Indias $\mathrm{u}$ en otra parte del mundo. El hospital prefería para este cargo mujeres de mediana edad, entre los 40 a 50 años. Cualquier mujer que se considerase capaz de ejercer el cargo presentaba un memorial, solicitando la plaza al haberse enterado de la vacancia de la misma. Algunas aspirantes a "madres de hospital" eran parientes o conocidas de ministros mayores o menores que habían trabajado muchos años en el hospital, los que les avisaban de los trabajos y las avalaban ante los patronos. Se dio el caso que se crearon trabajos para algunas de ellas. De esta manera nos encontramos con sobrinas de administradores, hijas de boticarios y hermanas de madres mayores. Por deferencia a estos ministros mayores al morir se asignaba a sus parientes féminas una habitación en el hospital donde vivir, incluida ración de comida. Algunas de estas mujeres aprovechaban su estadía para trabajar y recibir un salario por ello. El caso más notable fue de Lucia Pérez, hija del boticario Juan Pérez que había trabajado muchos años en el hospital. Al morir, su hija pidió una ración de pan y carne y un cuarto donde vivir dentro del hospital. Sin embargo, se le dio una habitación, pero no ración de comida, debido a la mala situación económica del hospital, por lo que tuvo que trabajar en el hospital como madre ayudanta de madre mayor, incorporándose como tal en 1700, trabajando hasta 1737 cuando fue jubilada. Se le designó un "cuarto dentro de la casa de mujeres o en las viviendas que tenía el hospital afuera de la portería, si no

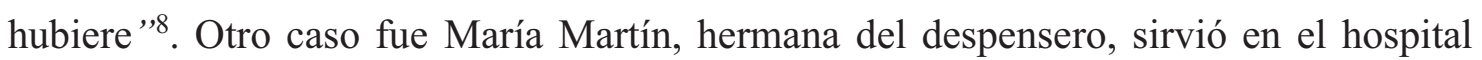
desde 1722 hasta 1730 cuando murió como madre convaleciente.

Un documento testimonia que algunas madres fueron hijas de ministros que trabajaron en el hospital fue el caso de María de la Concepción Zas, hija del botiller, que vivía con su padre en el hospital. En el memorial presentado para la plaza de madre enfermera, indicó "tener noticia” de la jubilación de una y alegó los méritos y años de antigüedad de su padre con más de 40 años de servicio 9 .

\footnotetext{
${ }^{8}$ ADPS. Libro de actas capitulares (1687-1715), f.82r (1698); Legajo 4A. Autos capitulares (1584-1635), f.61v (1606). Otro caso fue el de Isabel de Orellana, madre de sala, pariente del administrador Pedro Antonio Orellana quien, en 1606, fue removido de su cargo por los priores de Isidoro del Campo y San Jerónimo, el patrono de la cartuja se opuso a la medida. Corrió la misma suerte la madre enfermera mencionada ${ }^{9}$ ADPS. Legajo 4C. Libro de acuerdos capitulares (1800-1831), f. 156 r (1830): "Concedida la gracia a la dicha, atendidos los buenos servicios con que acreditó su conducta los muchos años que sirvió al hospital el padre de la que suplica, y la buena conducta de ésta, se le confiere el destino que solicita...”
} 
Los patronos de los tres monasterios, Santa María de las Cuevas, San Jerónimo y San Isidoro del Campo eran los que nombraban y rescindían a los ministros mayores notario secretario, mayordomo, curas, médico, cirujano, boticario, sangrador, abogado, procurador de pleito, escribano público, notario de apelaciones y maestros mayores de albañilería y carpintería-, siendo considerada como tal en el área de mujeres sólo la madre mayor. El administrador del hospital nombraba y despedía a los ministros inferiores como eran las madres auxiliares: ropera, agonizante, cirujana, panetera, convaleciente, enfermera, portera, tornillera y a las doncellas o sirvientas (Rivasplata 2012: 113-114) ${ }^{10}$. Según los estatutos del hospital, en estos cargos no se admitían recomendados, sin embargo esto no correspondía con la realidad, según se ha indicado anteriormente. Así, algunos ministros que trabajaron por mucho tiempo en el hospital solían colocar a sus parientes en algún trabajo en el hospital. Aunque esta práctica se trató de controlar, no tuvo éxito, llegándose a tachar con tinta está prohibición de la misma constitución de 1734. Finalmente, este hospital tenía un lugar reservado -el área de incurables-para las madres que habían alcanzado la vejez en el oficio con achaques y limitaciones.

\subsubsection{Las doncellas de dote}

Este hospital entregó ayudas de casamiento a sus criadas, a la usanza de un contrato de crianza y aprendizaje. Las "madres" enseñaban a las "hijas" o doncellas de dote el oficio al que fuesen destinadas, atención al enfermo, cocina, lavado de ropa, elaboración del pan. Una practica realizada en algunos hospitales desde la Baja Edad Media (Cabré 2005: 640). Las dotes a doncellas que trabajaron en este hospital duraron más de dos siglos (1587-1811), satisfaciendo la demanda social de dotar a doncellas púberes pobres para tomar estado de casada. También, este hospital regido por religiosos quería fomentar el casamiento público, tal como indicaba el Concilio de Trento (Campo 2004: 206). Este hospital ofrecía dotes, el aprendizaje de un oficio y un lugar donde vivir en reclusión de

\footnotetext{
${ }^{10}$ Las madres eran despedidas cuando no cumplían con sus obligaciones o por cometer infracciones.
} 
forma temporal en el área femenina del hospital. Las doncellas de dote permanecían el tiempo estipulado (tres años) y se marchaban, aunque algunas se quedaban en el hospital, en forma permanente para ser madres enfermeras. Aproximadamente, se entregaron 599 dotes a lo largo de 224 años, otorgados por el hospital y los distintos patronatos que lo eligieron como administrador de sus dotes. Estas mujeres anhelaban casarse, cumpliendo con todos los rituales al menos en Sevilla, aportando dotes simbólicas y un ajuar que reforzaran la idea de ser mujeres honestas aunque pobres y confiriendo a sus matrimonios un valor formal, social y legal intrínseco a diferencia de las uniones de hecho.

Las doncellas de dote aparecieron en 1587 a pedido de la madre mayor Jerónima de San Bernardo y también como consecuencia del Concilio de Trento, pues una institución regida por eclesiásticos tenía el deber de propiciar la difusión del matrimonio católico entre los pobres, propensos a la mancebía ${ }^{11}$.

Al ingresar al hospital la niña entraba en el cargo que quedaba vacante de las doce que había. Había una lista de espera y mientras tanto podían trabajar como "mozas sueltas" o "supernumerias". Las doncellas cumplieron funciones básicas de vigilancia al enfermo, asistencia inmediata, confortar con su presencia a las enfermas, atender a los convalecientes, hacer las camas, bañar a los enfermos, alimentarlos, dar las medicinas, unciones y regalos (bizcochos, azúcar, chocolate) indicados por la madre mayor, vestirlos, recoger sus excrementos y orinales, envolverlos en sudarios, velarlos, realizar la limpieza de las enfermerías, cocinar y lavar la ropa, es decir, según fuese designada como doncellas de medicina, cirugía, cocina, lavado y ropería. Las dotes eran financiadas por diferentes patronatos como el de Juana de Gallegos, las hermanas Núñez Pérez, la de Diego de Yanguas y por el mismo hospital.

Las doncellas de dote tenían que cumplir con una serie de requisitos para poder ingresar al hospital, proceder de padres casados y haber sido bautizadas. Las que no cumplían con estos requisitos podían trabajar en el hospital como criadas.

\footnotetext{
${ }^{11} \mathrm{Si}$ bien es cierto que las dotes de doncellas se entregaban desde antes del mencionado concilio, se incrementaron visiblemente desde finales del XVI, alcanzando su cenit en el siglo XVII.
} 
Tabla I. Las madres y las mozas que trabajaban en la enfermería femenina según la constitución de 1603

\begin{tabular}{|c|c|c|c|}
\hline Madre a cargo & Lugar de trabajo & Actividades de la doncella de dote & $\mathrm{N}^{\mathrm{o}}$ de mozas \\
\hline $\begin{array}{l}\text { Madre mayor o } \\
\text { madre de llaves }\end{array}$ & Toda la clausura ${ }^{12}$ & -- & -- \\
\hline Enfermera mayor & Cuarto de medicina & Ayudar a la madre enfermera & 5 mozas \\
\hline Madre cirujana & Cuarto de San Juan & Ayudar a la madre cirujana & 3 mozas \\
\hline Madre panetera & $\begin{array}{l}\text { Panetería, colindante a la } \\
\text { atahona "en la casa donde } \\
\text { amasan", }\end{array}$ & $\begin{array}{l}\text { Tamizar, cernir y amasar el pan y lavado de ropa } \\
\text { de toda la enfermería y toda la casa }\end{array}$ & 3 mozas \\
\hline Madre ropera & ropería & $\begin{array}{l}\text { Ayudar a la madre ropera en coser y remendar la } \\
\text { ropa que la madre ropera recibía de las distintas } \\
\text { oficinas }\end{array}$ & $1 \mathrm{moza}$ \\
\hline Madre portera & Puerta y torno & $\begin{array}{l}\text { Ayudar a la portera que tenía que ser una anciana, } \\
\text { fiel y de confianza y ayude a la madre de llaves } \\
\text { Cuidar el corral de las gallinas } \\
\text { Ayudar a la portera a entregar la comida a los } \\
\text { criados para los eclesiásticos (administrador, cura } \\
\text { y secretario) }\end{array}$ & $1 \mathrm{moza}$ \\
\hline Madre cocinera & cocina & $\begin{array}{l}\text { "Guisar de comer" a las enfermas y sanos, según } \\
\text { parecer de la madre de llaves }\end{array}$ & $\begin{array}{l}1 \text { moza y } \\
1 \text { muchacha }\end{array}$ \\
\hline 7 madres & & & $\begin{array}{l}14 \text { doncellas } \\
\text { de dote. } \\
1 \text { muchacha }\end{array}$ \\
\hline
\end{tabular}

Fuente: ADPS. Legajo 1 A. Constitución de 1603.

${ }^{12}$ ADPS. Legajo1. Constitución del Hospital de las Cinco Llagas 1503. Desde 1503, denominaron al área femenina "la clausura". 
Tabla II. Las madres y las mozas que trabajaban en la enfermería femenina según la constitución de 1624

\begin{tabular}{|c|c|c|c|}
\hline Madre a cargo & Lugar de trabajo & Actividades de la doncella de dote & $\mathrm{N}^{\mathrm{o}}$ de mozas \\
\hline Madre mayor & Toda la clausura & $\begin{array}{l}\text { Cuidar el corral de las gallinas y de dar de comer al } \\
\text { administrador, cura y secretario. } \\
\text { Ayudar en las almonedas de los vestidos de las difuntas. } \\
\text { Acompañar a la madre mayor en su visita a las enfermerías } \\
\text { y oficios de mujeres. }\end{array}$ & 1 doncella \\
\hline Enfermera mayor & Cuarto de San Pedro & $\begin{array}{l}\text { Ayudar a la madre enfermera para cumplir con } \\
\text { puntualidad las unciones, remedios y servicios. Ayudar a } \\
\text { repartir las comidas. }\end{array}$ & 5 hijas \\
\hline Madre cirujana & Cuarto de San Juan & $\begin{array}{l}\text { Ayudar a la madre cirujana en asistir a las enfermas, } \\
\text { ayudar a repartir la comida. }\end{array}$ & 2 hijas \\
\hline Madre ropera & Ropería & $\begin{array}{l}\text { Ayudar a la madre ropera en coser y remendar la ropa que } \\
\text { la madre ropera recibía de las distintas oficinas y hospital. } \\
\text { Ayudar a hacer colchones y lavar la ropa de los ministros } \\
\text { mayores (clérigos). }\end{array}$ & 1 hija \\
\hline $\begin{array}{l}\text { Madre del buen } \\
\text { morir }\end{array}$ & Cuarto de San Pablo & & Ninguna \\
\hline Madre panetera & $\begin{array}{l}\text { Panadería y horno } \\
\text { de la casa }\end{array}$ & $\begin{array}{l}\text { Amasar el pan necesario para el uso de la casa y lavado de } \\
\text { ropa de las enfermerías y criados de la casa. }\end{array}$ & 4 hijas \\
\hline \multirow[t]{2}{*}{$\begin{array}{l}\text { Dos } \\
\text { Madres cocineras }\end{array}$} & Cocina grande & $\begin{array}{l}\text { Ayudar a guisar las comidas de enfermería y criados del } \\
\text { hospital. }\end{array}$ & 1 hija \\
\hline & Cocina del tornillo & $\begin{array}{l}\text { Ayudar a guisar la comida del administrador, clérigos y } \\
\text { madre mayor. }\end{array}$ & 1 hija \\
\hline Madre portera & Puerta y tornillo & & Ninguna \\
\hline 9 madres & & & $\begin{array}{l}15 \text { hijas o } \\
\text { doncellas de } \\
\text { dote }\end{array}$ \\
\hline
\end{tabular}

Fuente: ADPS. Legajo 1A. Constitución de 1624. 
Tabla III. Las madres y las mozas que trabajaban en la enfermería femenina en 1734

\begin{tabular}{|c|c|c|c|}
\hline Madre a cargo & Lugar de trabajo & Actividades de la doncella de dote & $\mathrm{N}^{\circ}$ de mozas \\
\hline Madre mayor & Toda la clausura & $\begin{array}{l}\text { Cuidar el corral de las gallinas y de dar de comer al } \\
\text { administrador, cura y secretario. } \\
\text { Ayudar en las almonedas de los vestidos de las } \\
\text { difuntas. } \\
\text { Acompañar a la madre mayor en su visita a las } \\
\text { enfermerías y oficios de mujeres. }\end{array}$ & $\begin{array}{l}\text { Madre } \\
\text { ayudante de } \\
\text { madre mayor }\end{array}$ \\
\hline Enfermera mayor & Cuarto de San Pedro & $\begin{array}{l}\text { Ayudar a la madre enfermera para cumplir con } \\
\text { puntualidad las unciones, remedios y servicios. } \\
\text { Ayudar a repartir las comidas. }\end{array}$ & 5 doncellas \\
\hline Madre cirujana & Cuarto de San Juan & $\begin{array}{l}\text { Ayudar a la madre cirujana en asistir a las enfermas. } \\
\text { Ejecutar los remedios, que dejare dispuestos el } \\
\text { cirujano, teniendo prevenidas las vendas e hilos, y todo } \\
\text { lo demás, que hubiere menester } \\
\text { Ayudar a repartir la comida. }\end{array}$ & 1 doncella \\
\hline Madre ropera & $\begin{array}{l}\text { Ropería y cuarto de } \\
\text { lavado }\end{array}$ & $\begin{array}{l}\text { Ayudar a la madre ropera en lavar la ropa de sacristía, } \\
\text { la ropa blanca de todo el hospital y entregarla } \\
\text { compuesta. }\end{array}$ & 4 doncellas \\
\hline $\begin{array}{l}\text { Dos Madre } \\
\text { agonizantes }\end{array}$ & Cuarto de San Pablo & & Ninguna \\
\hline $\begin{array}{l}\text { Dos } \\
\text { Madres cocineras }\end{array}$ & Cocina grande & $\begin{array}{l}\text { Ayudar a guisar las comidas de enfermería y criados } \\
\text { del hospital. }\end{array}$ & 1 doncella \\
\hline & $\begin{array}{l}\text { Cocina del Tornillo y del } \\
\text { Calderillo }\end{array}$ & $\begin{array}{l}\text { Ayudar a guisar la comida del administrador y } \\
\text { eclesiásticos y madre mayor (Tornillo). } \\
\text { Guisar la comida del Boticario, Botiller, Madre } \\
\text { partera, y Tornillera, y a la Doncella de sala, teniendo } \\
\text { obligación de asear la loza de dichos ministros } \\
\text { (Calderillo) }\end{array}$ & 1 doncella \\
\hline
\end{tabular}




\begin{tabular}{|l|l|l|l|}
\hline Madre portera & Puerta y tornillo & & Ninguna \\
\hline $\begin{array}{l}\text { Madre de } \\
\text { convalecientes }\end{array}$ & $\begin{array}{l}\text { Cuarto } \\
\text { convalecientes }\end{array}$ & $\begin{array}{l}\text { Una ejerce también funciones de lavado de ropa, de la } \\
\text { sección ropería }\end{array}$ & 2 doncellas. \\
\hline 10 madres & & & $\begin{array}{l}14 \text { doncellas } \\
\text { de dote del } \\
\text { hospital }\end{array}$ \\
\hline
\end{tabular}

Fuente: Biblioteca Colombina. Constitución del Hospital de las Cinco Llagas de 1734. Fondo Gestoso V

\subsection{Las enfermas}

Según indica la bula de Alejandro VI, este hospital era necesario en una ciudad como Sevilla donde había una importante población femenina (Navagero 1983: 39) ${ }^{13}$ y "a la cual de diversas partes del mundo, cada día concurre gran muchedumbre de gente" (Domínguez 1992: 13) ${ }^{14}$, lo cual resulta cierto y se comprueba en los libros de entrada y salida del hospital donde consta que a finales del XVI y comienzos del siglo XVII, en plena bonanza económica sevillana, concurrían a ella mujeres de diferentes lugares de la Monarquía Hispánica y del extranjero como Francia, Alemania e Italia. El porcentaje de enfermas sevillanas, capital, era bajo, siendo la mayoría proveniente de los alrededores de Sevilla, así como Huelva, Córdoba, Badajoz, Extremadura, seguidas de diferentes partes de la península, inclusive Portugal que pertenecía, en aquel entonces, a España. La mayor parte de mujeres atendidas en el hospital eran inmigrantes, tal cual indicaba la bula de fundación. Inclusive, eran atendidas moras, mulatas y negras libres, además de algunos clérigos moribundos que eran traídos a la enfermería de eclesiásticos del hospital. Así, en 1608, ingresaron 1341 enfermas, de las cuales 262 eran oriundas de Sevilla y 8 de Triana (20\% del total). Ingresaron ese año al hospital un $4.47 \%$ de extranjeras (63 enfermas),

\footnotetext{
${ }^{13} \mathrm{Y}$ también porque muchas mujeres de áreas colindantes y rurales iban a Sevilla a trabajar para capturar algo del naciente desarrollo económico del Puerto de Indias.

${ }^{14}$ ADPS. Legajo 1B. Traslado de la Bula de Alejandro VI, de erección del Hospital de las Cinco Llagas, 13 marzo 1500 (doc.2). Sevilla alcanzó en el siglo XVI, su máxima población con 150.000 habitantes que sólo le aventajaba Paris y Nápoles. La gran peste de 1649 y el descenso económico hizo que descendiera en el XVII a 75.000 habitantes y durante el reinado de Carlos III (1759-1788) superó los 80.000.
} 
que se reduciría a $1.71 \%$ si consideramos que 37 enfermas provenían de Portugal y una de las cuales de sus colonias, que en aquel entonces pertenecía al Monarquía Hispánica. Las extranjeras provenían de Milán, Venecia, Alemania la Alta, Paris y Picardía. Algunas enfermas eran esclavas, oriundas de Guinea. E1 75\% restante provendrían de la Península Ibérica, principalmente de Andalucía Occidental y tres provenían de las Indias (Panamá y Cholua).

Después de la peste de 1649 se produjo una disminución drástica de enfermas. Así en el año de 1650 ingresaron sólo 571 enfermas y provenían de 115 pueblos diferentes, pero la atracción era preferente andaluza.

Tabla IV. Enfermas que ingresaron al Hospital de las Cinco Llagas de Sevilla en 1650

\begin{tabular}{|c|c|c|c|}
\hline Lugar & $\begin{array}{l}\mathrm{N}^{\mathrm{o}} \text { de } \\
\text { enfermas } \\
\text { por } \\
\text { pueblo }\end{array}$ & $\begin{array}{l}\text { Número } \\
\text { de } \\
\text { pueblos }\end{array}$ & Total \\
\hline Sevilla & 253 & 1 & 253 \\
\hline Triana & 18 & 1 & 18 \\
\hline Écija & 14 & 1 & 14 \\
\hline Jerez de los Caballeros & 13 & 1 & 13 \\
\hline Carmona & 12 & 1 & 12 \\
\hline Madrid & 11 & 1 & 11 \\
\hline Utrera, Granada & 10 & 2 & 20 \\
\hline Córdoba & 9 & 1 & 9 \\
\hline Lisboa (Portugal) & 8 & 1 & 8 \\
\hline Llerena, Sanlúcar de Barrameda, Aracena, Galicia & 7 & 4 & 28 \\
\hline Lora, Zafra, Cazalla & 6 & 3 & 18 \\
\hline Valladolid, Alcalá de Guadaira, Montilla & 5 & 3 & 15 \\
\hline Valencia, Extremadura, Jerez de la frontera, Morón, Fregenal, Osuna, Málaga, & 4 & 7 & 28 \\
\hline $\begin{array}{l}\text { Pedroso, Alcolea, Almendralejo, Loja, Marchena, Guévar del Algarafe, Lepe, } \\
\text { Rinconada, Higuera, Cantillana. }\end{array}$ & 3 & 10 & 30 \\
\hline $\begin{array}{l}\text { Biskaia, Santiago de Galicia, Ciudad Real, Bayona, Almagro, Villaverde(Madrid), } \\
\text { Santa Olalla(Toledo), Burguillos, La Puebla de Cazalla, La Palma, Guadalcanal, } \\
\text { Mairena, Arahal, Valencina, Antequera, Constantina, Almonte, Cartaya, Marbella, } \\
\text { Escacena del Campo, El Ronquillo, Sanlúcar la Mayor o de Alpechín }\end{array}$ & 22 & 2 & 44 \\
\hline $\begin{array}{l}\text { Las Indias, Tavira (Portugal), Coruña, Pontevedra, Ferrol, Villalba, Villa de Viveiro } \\
\text { (Galicia), Tolinas (Asturias), Villaviciosa (Asturias), El Castaño, Aragón, Oliva, } \\
\text { Castilla la vieja, Montañas de León, Ávila, Salamanca, Ciudad Rodrigo, La }\end{array}$ & 1 & 76 & 76 \\
\hline
\end{tabular}




\begin{tabular}{|l|l|l|}
\hline Peña(Salamanca), Toledo, La Torre, Medina de Ríoseco (Valladolid), Codorniz \\
(Segovia), Cáceres, Jaca, Fernán Caballero, Los Santos, Segura de León(Badajoz), \\
Mérida, Villanueva, Villamartín, Valencia de Alcántara, Zalamea, Montalbán, \\
Guadix, Saldaña (Granada), Cádiz, Ronda, Tenerife, Santa Marta, San Juan del \\
Puerto, Umbrete, Linares, Paterna del Campo, Alderete, Gibraleón, Lucena, Alcalá \\
del Río, Olivares, La Campana, Isla de Cristina, Algaba, Villaviciosa de Córdoba, \\
Niebla, Tomares, Puerto de Santa María, Almonester (Huelva), Ayamonte, \\
Almadén, Campillos, El Coronil, Jaén, 15 sin determinar & & \\
\hline Total & & \\
\hline
\end{tabular}

Fuente: ADPS. Legajo 243. Libros de entrada y salida de enfermos 1648-1663

Un 45\% de las enfermas que ingresaron en 1650 provenían de la ciudad de Sevilla incluyendo Triana. El resto, 258 de enfermas, es decir el 43\%, procedían de Andalucía, y la mayoría de ellas de diferentes pueblos, destacando Écija, Jerez de los Caballeros y Carmona. Apenas el 12\%, es decir, 74 enfermas provenían del resto de España, destacando Galicia y Castilla la Vieja. Los portugueses y una de Indias que provenían del resto del mundo era menos del $1 \%$.

A mediados del siglo XVIII, específicamente en el año de 1762, el hospital recibió 821 enfermas de las cuales murieron 94, decir el 11\% del total. El 46\% de las enfermas provenían de la ciudad de Sevilla, el 47\% del resto de Andalucía, el 6\% de otras partes de la península y menos del 1\% de las mujeres que llegaron al hospital procedían del extranjero. Los lugares eran del Faro, Lisboa, Nápoles, Gante, Ceuta, Bruselas, del Perú (Guayaquil) y una esclava negra sin procedencia indicada ${ }^{15}$.

\footnotetext{
${ }^{15}$ ADPS. Legajo 247. Libros de entrada y salida, 1762, f.326 r. Pascuala Pérez natural de Guayaquil en el Perú hija de Pascual Pérez y de María Bermúdez en 7 de diciembre de 1762. Ocupó la cama 65. Murió el 19 de diciembre de 1762 .
} 
Tabla V. Enfermas que ingresaron al Hospital de las Cinco Llagas de Sevilla en 1762

\begin{tabular}{|c|c|c|c|}
\hline Lugar & $\begin{array}{l}\mathrm{N}^{\mathrm{o}} \text { de } \\
\text { enfermas } \\
\text { por } \\
\text { pueblo }\end{array}$ & $\begin{array}{l}\text { Número } \\
\text { de } \\
\text { pueblos }\end{array}$ & Total \\
\hline Sevilla ciudad & 375 & 1 & 375 \\
\hline Écija & 29 & 1 & 29 \\
\hline Carmona & 23 & 1 & 23 \\
\hline Córdova & 21 & 1 & 21 \\
\hline Utrera & 15 & 1 & 15 \\
\hline Granada & 14 & 1 & 14 \\
\hline Guillena & 12 & 1 & 12 \\
\hline Málaga, Valencia & 11 & 2 & 22 \\
\hline Hinojosa de Córdoba & 9 & 1 & 9 \\
\hline Osuna, Marchena & 8 & 2 & 16 \\
\hline Madrid, Jerez (no especifica) & 7 & 2 & 14 \\
\hline Cádiz & 6 & 1 & 6 \\
\hline $\begin{array}{l}\text { Alcalá de los panaderos, Algaba, Alcalá del Rio, Medina Sidonia, Arahal, Arcos, } \\
\text { Castro del Rio, Ayamonte, Sanlúcar la Mayor (antiguamente llamada Sanlúcar de } \\
\text { Alpechín), Villalba, Mairena de los panaderos }\end{array}$ & 5 & 11 & 55 \\
\hline $\begin{array}{l}\text { Burguillos, Jaén, Pilas, Sanlúcar de Barrameda, Castilblanco de los Arroyos, } \\
\text { Escacena del campo, Puerto de Santa María, Barcelona, Castilleja de la cuesta, } \\
\text { Algeciras. }\end{array}$ & 4 & 10 & 40 \\
\hline $\begin{array}{l}\text { Cazalla, Coria, Lucena, Castiblanco, Gelves, Villanueva, Brenes, Espartinas, } \\
\text { Santiago, Cantillana,Olivares }\end{array}$ & 3 & 11 & 33 \\
\hline $\begin{array}{l}\text { Alcolea, Morón, Aracena, Faro de Portugal, Oviedo, Rinconada, Bujalance, } \\
\text { Cuenca, Palacios, Torrenueva, Salteras, Vélez Málaga, Valencina, Higuera, Orce } \\
\text { en Granada, Fregenal, Fuentes de la campana, Alburquerque, Alcalá de Guadaira, } \\
\text { Los Santos de Extremadura, Plasencia, Retamal }\end{array}$ & 2 & 22 & 44 \\
\hline $\begin{array}{l}\text { Nápoles, Angarillas(obispado de Santander), Benalcázar, Bollullos de la } \\
\text { Mutación, Albuquerque, Santa Olalla, Palomares, Beget, Montilla, Yelmes } \\
\text { (Portugal), Dos hermanas, Aneida (reino de valencia), Zamora, Almonte, Martos, } \\
\text { Aznalcázar, Mérida, Trigueros, Aracena, Marbella, Albaida, Campofrío, Cañete, } \\
\text { Almendrejo, Gibraltar, Bornos, Alcalá la real, Lisboa, Tortosa, Santa Marta, } \\
\text { Hurones, San Roque, Flandes, Cabra en las alpujarras, Paterna en Valencia, } \\
\text { Ciudad Rodrigo, Valsequilllo de Extremadura, Villa mayor de Calatrava, } \\
\text { Antequera, Moguer, Manzanilla, Tarifa, Montalbán (Córdoba), Torreorgaz } \\
\text { (Cáceres), Alcalá de los Gazules, Alcolea, San Vicente de la Barquera (Santander), } \\
\text { Fuente Obejuna, Valladolid, Camas, Gante, Zafra, Pontevedra, Cuellar, Resolana }\end{array}$ & 93 & 1 & 93 \\
\hline
\end{tabular}




\begin{tabular}{|c|c|c|}
\hline $\begin{array}{l}\text { del Campo, Asturias, Alcira, Almonester la Real, Zaragoza, San Salvador de } \\
\text { Sobradas en Galicia, Beas (Huelva), Aragón, Umbrete, Carreira, Ceuta, La } \\
\text { Campana (Sevilla), Bruselas, Cortegana (Huelva), Cabezabellosa (Cáceres), } \\
\text { Guadix, Guadalajara, un pueblo en las alpujarras, Cumbres altas, Bilbao, una } \\
\text { esclava sin procedencia, } 18 \text { pueblos sin determinar }\end{array}$ & & \\
\hline Total & 70 & 821 \\
\hline
\end{tabular}

Fuente: ADPS. Legajo 247. Libros de entrada y salida, 1762

A finales del siglo XVIII, las sevillanas, oriundas de la capital, conformaban el mayor porcentaje de mujeres atendidas en el hospital, seguidas de inmigrantes que provenían de los pueblos de alrededores de Sevilla, Huelva, Córdoba, Cádiz, Málaga y, algunas, de otras partes de España. No aparecen portuguesas y poquísimas extranjeras. Se ha tomado una muestra para demostrar lo indicado, correspondiente al año de 1798. Ese año ingresaron 819 enfermas, de las cuales 375 eran oriundas de la ciudad de Sevilla, es decir el 46\% del total, y el $54 \%$ del resto de Andalucía Occidental (del área rural de Sevilla, Córdoba, Huelva, Cádiz, Badajoz) y poquísimas extranjeras, provenientes de Brabante de los Países Bajos y Paris. También, algunas enfermas eran de las Indias: Darién de Panamá y Veracruz de Nueva España ${ }^{16}$.

Este resultado concordaría con lo que los historiadores José Manuel Cuenca Toribio y Juan Ignacio Carmona García indican que Sevilla siguió siendo atractiva entre los emigrantes que procedían de las comarcas periféricas a la ciudad - La Sierra, el Aljarafe y la Campiña- y de Huelva, Cádiz y Extremadura, así como de Castilla la Vieja, León, Galicia y Valencia a pesar de la decadencia económica de la ciudad, a fines del XVIII y el primer tercio del siglo XIX. Así, el descenso poblacional era evidente de 80.598 en 1799 a 75.000 en 1821(Cuenca 1976: 17; Carmona 1976: 34- 35).

Generalmente la mayor proporción de enfermas que ingresaban eran casadas o solteras (Perry 1990: 157) ${ }^{17}$, en menor proporción viudas, designando en el asiento de cada una, el número de cama, el nombre y apellido de las enfermas, la procedencia, el

\footnotetext{
${ }^{16}$ ADPS. Legajo 248. Libro de entrada y salida de enfermos (1766-1798).

${ }^{17}$ Esta autora indica que en 1605 un 44\% de las mujeres admitidas en este hospital eran casadas; en 1655 el $36 \%$ eran casadas.
} 
nombre y apellido del esposo si era casada y de los padres si era soltera y la ropa que traía, a veces indica edad y ocupación del esposo o padre.

2.2. Amas de cría

Mujeres que criaban en forma temporal a los niños y niñas de las enfermas. Se les pagaba como gastos menudos o de despensa. En un comienzo el hospital creó el cargo de ama de cría, ${ }^{18}$ pero se decantaron por contratar mujeres para que los criaran a catorce reales el mes. Por ejemplo en 1604 se pagó a una mujer por los diez días que "crió" a una niña de enferma. En 1605 se dieron 14 reales a una mujer que "criaba" a una criatura de una enferma del hospital. Incluso en 1606 se pagó dos reales a una mujer que dio leche a una criatura de enfermas. ${ }^{19}$ En el siglo XVIII se constata el envió de las criaturas a la casa de expósitos, conocida como Cuna. Por ejemplo, dos niños que nacieron en el hospital y cuatro niñas y un niño, que fueron traídos al hospital por sus madres enfermas fueron enviados a la Cuna en el año de $1762 .^{20}$

\subsection{Comadres}

Las comadres o comadronas realizaban lo que los médicos tenían prohibido hacer que era el parto de las enfermas. Estas mujeres venían periódicamente al hospital con el

\footnotetext{
${ }^{18}$ ADPS. Legajo 107. Libro de recibo y gastos, 1565, s/f. Ama que cría los niños.

${ }^{19}$ ADPS. Legajo 112. Libro de recibo y gastos, 1604 , s/f. 1605 ,f.73v y 1606, f.75r. Consignado en gastos extraordinarios. También en 1608, 1609 y otros años.

${ }^{20}$ ADPS. Legajo 247. Libros de entrada y salida de enfermas (1746-1765), f.309r. Una mujer de Sevilla parió una niña que se bautizó en San Gil. María Manuela, cuna; f.312v. Trajo un niño bautizado en Santiago de Carmona -Joan Joseph Carmona) f.327r. Trajo un niño bautizado en Guillena, Juan, cuna; f. 328r. Una mujer de Sevilla trajo una niña bautizada en Santa Ana, llamada María Magdalena. Cuna; f.330r. Una mujer de Sevilla parió un niño que se bautizó en San Gil, llamado Joseph se llevó a la cuna;_f.332v.Una mujer de Pilas trajo una niña bautizada, María, cuna; f.333v. Una mujer de Jerez trajo una niña bautizada, cuna.
} 
trabajo expreso de ayudar a parir a las gestantes, recibiendo cuatro reales por parto ${ }^{21}$. Su trabajo está presente en el libro de recibo y gasto como "gastos extraordinarios" y a veces como "gastos de despensa", es decir gastos menudos que hacía el hospital. No figura en el libro de salarios ya que este hospital tenía prohibido el ingreso de embarazadas, pero fue en vano, pues la realidad se impuso y su presencia fue tan cotidiana como la del médico o cirujano. Llama la atención la marginalidad en la que se mantuvo a las comadronas en los libros del hospital.

El hospital no realizaba partos, pero si recibía mujeres parturientas enfermas, asistiéndolas durante el parto y haciéndose cargo de los niños nacidos, remitiéndolos a la casa de niños expósitos o Casa Cuna, con certificación del cura, y en caso que no se le admitiese, se le buscaba ama para que lo criara a costa de este hospital durante el tiempo, que la madre pertenecía enferma, y no teniendo sus padres caudal para ello. Y lo mismo se ejecutaba con las criaturas que traían sus madres al pecho, y venían enfermas a curarse.

En 1727, se prohibió fehacientemente recibir mujeres a punto de parir en el hospital, alegando como fundamento que iba "contra el decoro... sobre las indecencias que ocasiona tal función a las doncellas sirvientas" (Perry 1996: 65) ${ }^{22}$. Se podían recibir mujeres embarazadas que habían sufrido algún accidente y si parían se las ubicaba "en un sitio separado de las enfermeras" según indicación de la madre mayor ${ }^{23}$.

\subsection{Huéspedes}

Había huéspedes que podían estar hasta un máximo de dos días, como las parientas de las doncellas de dote, en este caso el hospital asumía los gastos. Las licencias para

\footnotetext{
${ }^{21}$ ADPS. Legajo 112. Libro de recibo y gastos, 1605, f.73v. Consignado en gastos extraordinarios. "A una comadre que vino al parto de una enferma cuatro reales", 1606, f. 67v."A una comadre de parir que curó una enferma cuatro reales"

${ }^{22}$ En una época en que se creía que las parteras promovían la inmoralidad. El pecado de las parteras eran sus conocimientos, los cuales ayudaban a las mujeres que querían tener poder sobre su cuerpo y su sexualidad al saber practicas contraceptivas y abortivas.

${ }^{23}$ ADPS. Legajo 4B. Autos capitulares (1716-1734), f.83 r (1727).
} 
largas distancias otorgadas a ministros de la talla del administrador o de la madre mayor para albergar parientes se daban con la condición que los hijos o hijas asumieran los gastos. Por ejemplo: la madre mayor Victoria Sevillano y la madre ayudante Juana Sevillano, hermanas, albergaron en calidad de morador y comensal del hospital a su padre Andrés Sevillano, quien vivía a expensas de su hija, la madre mayor. Murió en 1778. El testamento de Andrés Sevillano, "morador de este hospital" declaró que en el segundo matrimonio con "Jerónima Velázquez, aunque tuve varios hijos, sólo en el día me vive que es Da. Victoria Sevillano, de estado honesto, madre mayor que actualmente está siendo, en este dicho hospital y a cuyas expensas estoy viviendo" 24 .También el hospital pagaba a los mesones cercanos para que albergaran enfermas si es que no había cabida en el hospital. Así, en 1605 el hospital pagó real y medio de posada de tres enfermas que pernoctaron una noche en el mesón ${ }^{25}$.

\subsection{Donadas}

Una donada, que era una mujer seglar que se retiraba a los monasterios o casas de religión para servir a Dios y a los enfermos, trabajó en este hospital. En 1528, al morir, dejó sus bienes para pagar anualmente a las mujeres que servían a las enfermas en el Hospital de las Bubas ${ }^{26}$. El Hospital de la Sangre pagaba al mayordomo del Hospital de las Bubas una donación de 600 maravedíes a nombre de la madre donada que murió en el Hospital de la Sangre. El capital era unas casas que legó a este hospital de la cual obtenía la mencionada renta que se continuaba dando en 1567.

\subsection{Las beatas}

\footnotetext{
24 ADSP. Legajo 263. Memorias, testamentos, almonedas de bienes de difuntos. Siglos XVI-XVIII. Testamento de Andrés Sevillano, natural de la villa de Santiponce, viudo de María Amaya. Otorgado en 28 de julio de dicho año ante el padre cura don Bartolomé de Guzmán.

${ }^{25}$ ADPS. Legajo 112. Libro de recibo y gastos, 1605, f.73v. Consignado en gastos extraordinarios.

${ }^{26}$ ADPS. Legajo 107. Libro de "recibo y gasto" (1528), f.106.
} 
En el hospital había beatas, las que no habían realizado voto de obediencia a ninguna regla (Perry 1990: 101). Algunas de ellas atendían a las agonizantes. En el siglo XVII, destacan madres beatas como la madre cirujana María de San Joseph que había trabajado en cirugía quince años (1620 a 1635). Algunas jefas del área femenina del hospital eran beatas, como la madre mayor Jerónima de San Bernardo (1587-1589). Otra beata fue Victorina de los Dolores Sevillano trabajaba en el Hospital del Pozo Santo ${ }^{27}$ cuando fue nombrada madre mayor del hospital de la Sangre de 1776 a 1782.

\subsection{Criadas}

El hospital tuvo necesidad de criadas. De 1500 a 1587, las jóvenes que trabajaban en el hospital eran criadas, después aparecieron las doncellas de dote, pero no todas las jóvenes podían optar a esta situación, pues tenían que cumplir con una serie de requisitos, por eso el hospital continuó haciendo uso de criadas. El administrador recibía criadas de servicio según las necesidades del hospital para que las cosas estuviesen "bien hechas y con mucha limpieza" ${ }^{28}$. En 1572, se menciona a una criada, llamada Catalina Morena quien solicitó una ayuda a su casamiento a los patronos del hospital por haber servido "con mucho cuidado a los pobres en el hospital mucho tiempo desde los tiempos de peste", consistente en una cama que costaba 13 reales $^{29}$. Este dato es de suma importancia porque nos indica que aún no se habían establecido las dotes a doncellas en el hospital. La documentación menciona a diferentes tipos de mujeres que ejercieron este trabajo, podían ser pobres, mujeres solas, viudas que se ofrecían a trabajar en el hospital. A comienzos del siglo XVII, se encuentra el caso de Estebania de Salas que según su testamento realizado en 1606 indica que fue criada del hospital. Este documento fue

\footnotetext{
${ }^{27}$ ADPS. Legajo 4B. Libro de Auto Capitulares (1764-1787), f76 r (1776): “... estando informados de la capacidad y demás buenas prendas, que le asisten a la madre Victorina de los Dolores, que actualmente se halla en el hospital del Pozo Santo..."

${ }^{28}$ ADPS. Legajo 4A. Autos capitulares (1584-1635), f.41 v (1603).

${ }^{29}$ ADPS. Legajo 1 B. Autos capitulares (1556-1584), f.53 r (1572).
} 
realizado por el cura, teniendo como testigos a sus compañeras de trabajo, dos doncellas enfermeras de dote y la madre de sala Isabel de Orellana. Estebania era viuda de Antonio de Villalba y vecina de la ciudad de Sevilla y dejó todos sus bienes para misas por su alma y para poder ser enterrada junto a su hija en la cripta del hospital. Se hizo un inventario de sus cosas para venderlas en subasta pública en el hospital. Se trataba de su ajuar compuesto por una cama con dos colchones, sabanas, almohadas, toallas, escalera, candelero, una verónica, un retablo, tres tocas, una gorguera, dos camisas, un fustán, ropa y mangas de lanilla, una saya de bayeta negra, un manto de anascote, unos chapines, un delantal, un espejo, una tabla de manteles y dos servilletas, un lebrillo y una mesa de lavar, dos sillas, anafes y asadores. También tenía joyas: unas sortija verde y otra de amatista, crucifijo de oro, una gargantilla de perlas y cuentas de oro ${ }^{30}$. Esta mujer es un reflejo de la bonanza económica que gozó Sevilla a finales del siglo XVI, su situación dista mucho de las criadas del siglo XVIII. Así, en la documentación, se les menciona sólo por su nombre de pila sin apellido como Ángela e Isabel, criadas de casa en 1735. Eran muy pobres quizá recogidas sin padres conocidos. Algunas madres le regalaban cosas en sus testamentos. No participaban en las almonedas por no tener dinero para eso. No consta que el hospital les pagase. Se les pagaba, dándoseles cobijo y alimentación. Mujeres de pobreza absoluta. Uno de los pocos documentos donde aparecen es en la almoneda y testamento de la madre tornillera Catalina Lechuga en $1735 .^{31}$

Las criadas podían ser contratadas a título personal por algún trabajador del hospital, sin que el hospital tuviese alguna responsabilidad sobre ellas. Así, en 1600, el veedor de la casa hospital Juan Barreda pidió ración para su criada, no se lo dieron. Sin embargo, en 1749, el hospital permitió que una criada de un administrador pasara los últimos años de su vida en una cama de incurable. Había casos en que algunos ministros tenían criadas de día, hasta pernoctaban en sus cuartos de noche, contra lo ordenado por las constituciones y venerable práctica. Se hacían llamadas de atención a los ministros de

\footnotetext{
${ }^{30}$ ADPS. Legajo 1 A, Testamento de la criada Estebania de Salas 1606, folio suelto; Legajo 242. Libro de entrada y salida de enfermas, 1606, f. 94r. Estafania de Salas de Sevilla, viuda de Antonio de Villalba, entró en 15 días de junio de 1606. Murió en 18 de junio de 1606.

${ }^{31}$ ADPS. Libro 207. Libro testamentos y memorias de enfermos y enfermas del Hospital de la Sangre (1693-1763).
} 
no hacer uso de criadas, sino de criados: "No habiten con mujeres extrañas aunque sean de mejor fama y honor, sino solamente con sus madres y hermanas" 32 .

En este hospital, cualquier mujer podía ascender, si demostraba fidelidad y trabajaba mucho para el hospital. Fue el caso de Mariana de Mora, criada de la madre ropera que asumió la jefatura del área de ropería, como madre ropera desde 1637 hasta 1650.

\subsection{Mendigas}

Se recogían mendicantes de la calle. Así, se solicitaban camas de incurables a algunas de estas mujeres avaladas por los curas del hospital. Tenemos el caso de Gertrudis Rodríguez, natural de Sevilla, parroquia el San Lorenzo frente de la calle y plazuela de los Tiros en la casa $n^{\circ} 15$. Estaba casi ciega, huérfana de padre y madre. Era tan pobre que mendigaba por la ciudad, había sido atropellada varias veces por los coches y caballerías. No se podía asegurar el alimento diario. Se solicitaba para ella una vacante y nombramiento en la sala de incurables. Se pedía la certificación de ser pobre de solemnidad por el cura de la parroquia a la que pertenecía. Avalaron por ella, los curas del Hospital de la Sangre Juan Nepuceno y Meléndez Valdez. Solicitado en $1796^{33}$.

\subsection{Esclavas}

Había esclavas en el Hospital de la Sangre. Se donaron algunas para ese fin por voluntad testamentaria por la misma Catalina de Ribera, fundadora del hospital, quien donó a Juana e Isabel. El caso de Ana, la esclava, es peculiar porque el hospital pagó 50

\footnotetext{
${ }^{32}$ ADPS. Legajo 4C. Libro de Auto Capitulares (1788 a 1800), f.17 r (1790), f.74 r (1796).

${ }^{33}$ ADPS. Legajo 186. Tributos y aniversarios 1796. Papeles sueltos.
} 
ducados por su rescate a los moros, cantidad que tuvo que devolver la misma trabajando por cuatro años a doce ducados cada uno desde 1560 a 1563, siendo panetera menor, mayor y finalmente cocinera mayor. Cumplió y se fue. El hospital recibía por legado testamentario esclavas negras, que se vendían en forma periódica, pues los patronos no aceptaban que trabajasen en el hospital porque "así conviene para la buena administración del hospital"34. Por ejemplo, en 1689 se ordenó la venta de María de Regla, Rufina de Gracia de 28 y 19 años, y también de las niñas Teresa y Juana de 9 y 11 años. También, en 1772, las esclavas negras eran vendidas como el caso de Juana, la negra de Angola, por "no convenir" al hospital ${ }^{35}$.

En época de extrema crisis el hospital buscaba ingresos para mantenerse, siendo uno de ellos, las camas de incurables. Por lo que no dudó en admitir en el hospital, ocupando una de estas camas, una esclava turca blanca, María del Espíritu Santo desde 1710 al 18 de agosto de $1721^{36}$. No trabajó en el hospital por lo que pagó por su estadía y manutención.

En el siglo XVIII, llama la atención que si bien no había cabida para esclavas negras en el hospital, si la había para las de tez blanca. Se trata de otra esclava turca María Agustina, de nación turca, "vagante esclava de este hospital" 37 quien dejó un interesante testamento. Había estado sirviendo por años y llegando a la ancianidad, solicitó su libertad, pero no se la concedieron, sino el alivio a su carga de trabajo "en lo que hubiere lugar a discreción de la madre mayor y en cuanto a su libertad, no ha lugar" ${ }^{38}$. Participaba en las almonedas particulares de venta de bienes de difuntas. En 1742 mandó hacer el testamento y en 1746 se accidentó y modificó su testamento por dos veces, aunque no en lo sustancial. María Agustina, turca de nación, murió en 1754. Prestaba a todas las madres

\footnotetext{
${ }^{34}$ ADPS. Legajo 4B. Libro de actas capitulares (1687-1715), f.16 v (1689).

${ }^{35}$ ADPS. Legajo 4B. Libro de actas capitulares (1659-1687), f.113 r (1672): "Por cuanto el capitán Juan de Melo, vecino de la ciudad hizo donación y limosna a este hospital de una esclava nombrada Juana negra de nación de Angola de 26 años por instrumento otorgado ante Juan del Pino y Alcolea escribano público de Sevilla en 5 días del mes de noviembre 1671. Y por cuanto la dicha esclava no le es de conveniencia al dicho hospital. Daban y dieron facultad al Sr. administrador para que la venda en el precio que le pareciere y... a cualquier persona. Y que lo procedido de ella lo recibió el dicho Sr. administrador y entre el dinero en las arcas del hospital para que se haga cargo a su tiempo".

${ }^{36}$ ADPS. Libro de actas capitulares (1687-1715), f.237 v (1710).

${ }^{37}$ ADPS. Legajo 263. Memorias testamentos, almonedas de bienes de difuntos (XVI-XVIII), s/f.

${ }^{38}$ ADPS. Legajo 4 B. Autos capitulares (1716-1734), f.71 v (1725).
} 
y daba dinero para mejorar los ornamentos del altar mayor, como el cáliz y el Jesucristo de la escalera. Era una especie de usurera. A pesar de ser esclava se le pagaba por ser vagante, es decir, reemplazar en el trabajo a las madres y doncellas enfermas. La gran cantidad de misas y legados a santos demuestra que quería hacer constancia su cristiandad con mayor ahínco por el hecho de ser turca y esclava. Todo lo que tenía lo destinó para misas por su alma y su entierro en la iglesia del hospital.

Es importante indicar que hubo más esclavos en el siglo XVI que en siglos posteriores, cuando el hospital estaba en la parroquia de Santa Catalina. Por ejemplo, en 1558, el administrador tenía tres esclavos que posteriormente se cambiaron por lacayos, así, en 1573, se le dio un lacayo, un paje y caballerizo. Los patronos no querían esclavos negros en el hospital porque no los podían controlar.

\subsection{Enfermas libertas y negras libres nacidas en Sevilla}

El hospital recibía mujeres enfermas no contagiosas de cualquier color. Se han encontrado en el fondo archivístico del hospital testamentos de libertas. Josefa Manuela, negra atezada, libre y de estado doncella realizó su testamento en 1729, pidiendo ser enterrada en la iglesia del hospital y la realización de misas por su alma, pagado por la venta de sus bienes. Otra negra atezada natural de Brasil, Laureana de Jesús, realizó su testamento en 1730. Se hizo almoneda de sus bienes para poder ser enterrada en la iglesia del hospital y realizar misas por su alma. María de la Cruz, negra atezada, natural de Portugal, hija de padres no conocidos hizo testamento en 1738, declaró tener los siguientes bienes: una saya de esparragón de color de ámbar, naguas de esparragón verde, cuatro delantales de cocina, naguas de bayeta, una camisa, un manto, un pañuelo y calcetas. Su amo Luis de Zeballos, picador de la maestranza, le prometió costearle su entierro y misas. María Josefa de la Cruz, negra, nacida en Sevilla, cuyos padres fueron Antonio de Flores y María de la Cruz, hizo testamento en 1740. Tenía 25 años, era doncella. Se dedicaba a la venta ambulatoria de buñuelos. Pidió ser enterrada en la iglesia 
y se hicieran misas por su alma. Prácticamente gran parte de sus bienes estaban empeñados. Tenía un arca de cedro donde estaban un manto, saya de pelo de camello, un colchón, una sábana con encaje, una almohada de Bretaña con encaje, una arquilla, canastas, cubo, tinaja, lebrillo de hacer buñuelos, una tarimillas, siete camisas, diez corpiños, naguas blancas y azules, frasco de aceite, tarrito para meter el pan, un mantel, un farolillo, peana de palo, calcetas, abanicos, un delantal encarnado de moda, otro negro de tafetán, guantes... Vivía sola en un cuarto sobre el oficio de un zapatero remendón.

\subsection{Enfermeras extravagantes o vagantes}

Se trataba de las enfermeras temporales que no recibían cama ni ración de comida. Las que asistían por "emergencias" por algún accidente u otra causa. Las vacantes aparecieron en 1557, la primera de las cuales fue Francisca de Quiñones, ganando igual que cualquier criada 9 reales al mes. "Sirven todo lo que es menester, faltas de servidoras cuando alguna está enferma"39. Posteriormente, aumentaron en número. A pesar de su presencia permanente en el hospital, ninguna constitución las menciona.

Las "vagantes" ingresaban al hospital por estos motivos:

1) Para suplir a las madres y doncellas de la familia que estaban enfermas.

2) Para lavar la ropa.

3) Para limpieza de los cuartos de los ministros.

Sus salarios se abonaban en el libro de recibo y gasto del hospital.

Las madres y doncellas enfermas pagaban con sus salarios a las "vagantes", y el hospital pagaba sus haberes de sus fondos en caso de pestes y otras eventualidades. Se las solicitaba cuando había gran concurrencia de enfermas y trabajo en el hospital. Se las

\footnotetext{
${ }^{39}$ ADPS. Legajo 107. Libro de recibo y gasto de 1557.
} 
recibía por la falta que había de sirvientes y siempre que había necesidad de recibir otra se daba noticia al patrón presidente ${ }^{40}$.

2.14. Las doncellas supernumerarias o "Mozas sueltas"

Estas doncellas recibían salario (2.202 maravedies anuales), pero no ayuda de dote, ni ración de comida. Era la doncella que no había entrado aún en una plaza de doncella de dote y estaba a la espera de ello, mientras tanto realizaba labores de sirvienta, podía adquirir bienes en almoneda para descontárselo de su salario una vez que entraba en plaza. ${ }^{41}$ También eran llamadas mozas sueltas: "Título de mozas sueltas. En 31 de diciembre de 1607 se dieron a Francisca Magdalena 11 reales que ganó de salario un mes que sirvió en esta casa antes de entrar en oficio". Ingresó ese año como tercera hija de enfermera: "En 31de diciembre de1607 se le dieron a Francisca Magdalena que sirvió este oficio siete ducados con los cuales se le acabaron de pagar 132 reales que montó todo su salario de todo el dicho año a razón de once reales cada mes". Asimismo en 1607 se pagó a Juana Guerra 156 maravedies por trece días que trabajó antes de entrar como segunda hija de panadera donde ganaría 4.488 maravedíes anuales. ${ }^{42}$ Había años en que el número de mozas sueltas desbordaba a las que estaban en lista de espera para entrar como doncella de dote, así que se contrataba a jóvenes sin esta condición. Un caso interesante fue Catalina Jiménez que empezó a trabajar en el hospital como moza suelta en 1604 y por haber estado casada, ya no podía ser doncella de dote, pero ascendió ese año a jefa de $\operatorname{cocina}^{43}$.

\footnotetext{
40 ADPS. Libro de actas capitulares (1687-1715), f.53 v (1695).

${ }^{41}$ ADPS. Legajo 161. Libros de entrada y salida. Ano 1700, f.231 r: Adquirían cosas menudas y de bajo costo o muy viejas como peines, arquetas de pino, arquillas viejas.

${ }^{42}$ ADPS. Legajo 112. Libro de recibo y gasto de 1607, f. 150v y f.159r. f. 156 r.

${ }^{43}$ ADPS. Legajo 112. Libro de recibo y gasto de 1604, f. 147. En 31 de diciembre de 1609 le dieron a Catalina Ximenez ocho reales que trabajo como moza suelta, ascendió a madre cocinera y recibió 5.610 maravedies que pagaban a las jefa de cocina en ese año
} 


\subsection{Trabajadoras temporales}

En las enfermerías, se necesitaban trabajadoras temporales para lavar y limpiar las enfermerías durante el traslado de las enfermas (algunos días de los meses de junio y octubre), para hacer colchones, lavar la ropa y cocinar en fiestas que congregaba mucha gente (Quasimodo y Navidad). Se les pagaba como gastos extraordinarios, no entraban en salarios, pues eran trabajos puntuales en forma esporádica. Era común, blanquear o enjalbegar con cal de Morón o yeso las paredes de las enfermerias todos los años. Deshollinaban las enfermerías altas en octubre para quitar las manchas del carbón en las paredes y piso. Después lavaban y enjalbegaban las paredes, actividades realizadas antes de subir a las enfermas al empezar temporada de invierno. El lavado de las enfermerías no lo realizaban las doncellas, sino que se pagaban a mujeres u hombres a $2 \frac{1}{2}$ reales, además de comida y bebida. A finales del XVII, estaba a cargo de Josepha López, la cual también vendía escobones al hospital. Esta mujer traía consigo siete mujeres más para realizar la faena en tres días. Para la subida y bajada de enfermas se solía contratar a once o más costaleros. También se contrataban para lavar la ropa, colchones y coser ropa ${ }^{44}$. Lo que llama la atención es que llamaban a una mujer para curar landres que era una especie de tumor que salía en los sobacos, en las ingles y a veces en la garganta. Se podría tratar de una peste ${ }^{45}$.

2.16. Madres, hermanas y esposas de ministros mayores y menores que vivían en el hospital.

Aunque estaba prohibido que mujeres vivieran con los ministros mayores, principalmente, administrador y secretario, ocurría más de lo deseado. De esta manera a

\footnotetext{
${ }^{44}$ ADPS. Legajo 112. Libro de recibo y gasto de 1603, s/f. "Pagarosenle a dos mujeres que estuvieron lavando ropa cuatro días a dos reales y cuartillo cada una cada día son dieciocho reales", "De dos mujeres que lavaron las frezadas de la enfermería cuatro reales", "De una mujer que ayudo a lavar"; Legajo 112. Libro de recibo y gastos, 1608 , s/f. 63r.Una mujer que hizo colchones por un día se le pagó dos reales.

${ }^{45}$ ADPS. Legajo 112. Libro de recibo y gasto de 1603 , s/f. Una pareja curaba de landres según la documentación citada. "De una mujer que curó las enfermas de landres 18 días tres reales cada día", "De un hombre que estuvo curando los hombres que tuvieron landres doce días a dos reales cada día".
} 
pesar de las prohibiciones constitucionales, a los ministros mayores o menores se les compensaba por el buen servicio dado, permitiéndolos vivir con sus parientes. De esta manera en el hospital vivían mujeres no sólo en el área exclusivamente femenina, sino también en los cuartos del hospital donde vivían los ministros. En otros casos, se debía a que algunos ministros como médicos, cirujanos, despenseros, boticarios, botilleres, porteros y hortelanos estaban casados con mujer e hijos. Al morir los hombres, las viudas e hijos quedaban en situación de orfandad absoluta, haciéndose cargo de su manutención el hospital, de tal manera que se dio épocas en que había "familias de mujeres" conformada por viudas y sus hijos que vivían en el hospital. Llegó a tal punto que en 1722, se determinó su prohibición y extinción paulatina de esta situación. Dándose preferencia en el nombramiento a ministros célibes o solteros ${ }^{46}$. Sin embargo a pesar de las prohibiciones fue casi imposible evitarlo, los ministros laicos solían tener esposa e hijos y los religiosos madre y hermanas. Esto era una realidad palpable que superaba las continuas prohibiciones, por lo que en 1759 se determinó que los familiares alojados en el hospital al morir recibiesen la extremaunción de manos de los curas del hospital y se les enterrasen en el campo santo o cripta de la iglesia. Pedido que se reiteró en 1760. El patronato del hospital concebía a los familiares de sus ministros que vivían con ellos como parte de la familia hospitalaria, de tal manera que se les enterraban en el hospital sin gasto alguno y sin que los curas cobrasen derecho alguno. Previa licencia los ministros podían vivir con sus parientes femeninos ${ }^{47}$.

\footnotetext{
${ }^{46}$ ADPS. Legajo 4 B. Autos capitulares (1716-1734), f.54 v (1722): "Que de golpes y clausura fuera no haya más familia de mujeres que la de los ministros casados que hoy hay en los cuartos de continuo; pero que en muriendo estos si se casasen las viudas pierdan las plazas que ejercieren y se nombren solteros".

${ }^{47}$ Algunos ejemplos serian las siguientes: En la segunda mitad del siglo XVI fue más recurrente la presencia de parientes de los ministros mayores, que ocupaban puestos de trabajo importantes en el hospital, por ejemplo la familia Gallegos. En la época de mayor opulencia del hospital, en 1575, se dio licencia para que la madre del administrador, Francisca de Gallegos, pueda vivir y habitar en el hospital con las demás gentes que fueren necesarios a su servicio, pagando al hospital toda la costa. Habían trabajado como madres mayores las parientes de este administrador Ana y Constanza Gallegos. Asimismo, en 1748 se dio licencia a un cura Miguel García Bejarano para que viviese con su madre y hermana en un cuarto que estaba en el patio de la iglesia.
} 
2.17. Esposas de criados que trabajaban en el hospital

Este era otra situación recurrente en el hospital, en la que ambos cónyuges trabajaban en un mismo oficio. Algunos criados casados vivían con sus mujeres, así, el caballerizo y los porteros. Estas mujeres trabajaban ayudando en los oficios de sus maridos. En el caso de la esposa del caballerizo, ambos vivían fuera del hospital, específicamente en la parte de atrás donde se mantenían las caballerizas. La mujer, al morir el esposo, solía pedir raciones de comida de por vida que los patrones concedían. Por ejemplo, en 1673, Catalina López esposa, viuda de Antonio Fernández, caballerizo del hospital que sirvió 26 años, pidió merced de una ración de comida hasta el fin de sus días por pobreza. Alegó haber trabajado junto a su marido en el hospital por mucho tiempo. Se le entregó una libra de pan, una cuarta libra de carne de vaca o de puerco o pescado $^{48}$. Otro caso, en 1747 se dio licencia para que se casara al jardinero y portero Francisco del Puerto, con Gregoria, hija de Nicolás Pérez, también ministro del hospital. Ambos vivieron en el hospital y la hija de ambos fue doncella de dote en 1778. Al quedarse viuda Gregoria Pérez en 1780, el hospital le concedió una libra de pan diario para ella y sus hijos. Uno de sus hijos Joseph del Puerto fue portero a comienzos del siglo XIX.

2.18. Esposas, sobrinas "desamparadas" de ministros mayores o menores que habían trabajado en el hospital.

Esposas de criados como caballerizos, porteros; esposas de médicos y cirujanos, así como, sobrinas de ministros mayores como administradores, secretarios, mayordomos pedían al fallecer "sus hombres" "ayudas de costa" como de manutención con raciones de comida diaria o bien una cantidad de dinero anual. También, se entregaron dotes para monjas o de casada a estas mujeres procedentes de las obras pías de los patronatos. La

\footnotetext{
${ }^{48}$ ADPS. Legajo 4B. Libro de actas capitulares (1659-1687), f.119 v (1673).
} 
más célebre de todas fue María Escobar sobrina del secretario y mayordomo del hospital Francisco Pérez de Escobar quien había trabajado cuarenta años en el hospital y además era prima del administrador Mateo de Escobar quien había laborado hasta 1692. Al jubilarse a este administrador le dieron ración de comida y cincuenta ducados anuales, viviendo en una casa del hospital de la que no pagaban renta. Posteriormente, en 1696, el tío y primo de María de Escobar habían muerto, de tal manera que los patronos determinaron que mientras viviera en la ciudad de Sevilla, se le diese una limosna anual de 500 reales de vellón y cada día una hogaza de pan y media libra de vaca o de puerco o de pescado en los días de vigilia, con la condición que dejara la casa donde había vivido con sus parientes difuntos ${ }^{49}$. Sin embargo se la suspendieron en 1698 por la mala situación económica del hospital, entregándole sólo el dinero, sino se le devolvía la casa del hospital donde había vivido con sus parientes, teniendo que pagar su renta o sino conformarse sólo con los 500 reales que se le daban en compensación por la renuncia al derecho de la casa y las mejoras realizadas en ella. En 1701, María solicitó la entrega de su ración de comida, alegando vejez. Pedido que fue concedido. En 1711, a María de Escobar se le destinó una cama de incurables donde se le ayudaba con ración de comida, en vez del dinero que se le daba como situado. Al entregar la casa donde vivía, el hospital se comprometió a mantenerla hasta su muerte.

En la práctica, el hospital ayudaba a las hijas doncellas y viudas de ministros y criados que habían servido por mucho tiempo en el hospital y que, generalmente, fallecían antes que éstas. A lo largo de de tres siglos el hospital amparó a más de 56 parientes de ministros mayores y menores que quedaron en abandono.

Tabla VI. Mujeres y familiares de ministros, que fueron acogidas por el hospital en el siglo XVII

\begin{tabular}{|l|l|}
\hline Año & Beneficiadas \\
\hline 1604 & $\begin{array}{l}\text { Doña Mencía de Torres Carvajal, viuda del doctor Pedro Bermudo, pidió ayuda, dándosele 20 ducados } \\
\text { como ayuda de costa porque el marido había ejercido en el hospital, aunque tenía que devolver la casa } \\
\text { que el hospital asignó a la familia del médico mientras ejerciese. }\end{array}$ \\
\hline 1608 & $\begin{array}{l}\text { Teresa Cortes, viuda de Pedro López, pedía alguna limosna por haberse ahogado su marido en el río } \\
\text { bañando las cabalgaduras del hospital. Le dieron } 100 \text { reales. }\end{array}$ \\
\hline 1615 & Juana de Pina, madre de un prior de San Isidoro que murió, recibió 6 ducados Se le concedió dinero por \\
\hline
\end{tabular}

\footnotetext{
${ }^{49}$ ADPS. Legajo 4B. Libro de actas capitulares (1687-1715), f.59 r (1696).
} 


\begin{tabular}{|c|c|}
\hline & una vez, pero no ración de comida, tal como pidió. Alegó pobreza y vejez. \\
\hline 1617 & $\begin{array}{l}\text { Ana de los Ángeles, viuda de Simón García, barbero del hospital, recibió una limosna de } 100 \text { reales por } \\
\text { una vez. Ana Marina, viuda de un ministro, } 20 \text { ducados de limosna. }\end{array}$ \\
\hline 1618 & uda de despensero Fructuoso de Rivera, 20 ducados de limosna. \\
\hline 1619 & $\begin{array}{l}\text { María de Bocarando, madre de Ana de Bocarando, la madre mayor que fue del hospital, se le dio } 100 \\
\text { reales como limosna y María Ruiz, viuda del portero Esteban Lorenzo le dieron } 4 \text { ducados de limosna. }\end{array}$ \\
\hline 1621 & $\begin{array}{l}\text { Le dieron a Catalina García, que había servido en el hospital } 24 \text { años, } 200 \text { reales anual durante toda su } \\
\text { vida para su sustento, a modo de limosna por ser pobre y vieja. }\end{array}$ \\
\hline 1624 & $\begin{array}{l}\text { Catalina Sánchez se le dio limosna para su casamiento de } 150 \text { reales por ser pobre, por ser huérfana, por } \\
\text { haberse casado "bien" y porque sus padres Pedro Sánchez y Ana María fueron criados del hospital por } \\
\text { mucho tiempo. }\end{array}$ \\
\hline 1627 & $\begin{array}{l}\text { A la petición que dio doña Isabel de Almoguera, viuda del Dr. Carmona, médico que fue de esta casa, } \\
\text { los patronos le dieron como limosna } 200 \text { reales por una vez. }\end{array}$ \\
\hline 1630 & $\begin{array}{l}\text { Le dieron } 100 \text { reales a Beatriz de Pina, hermana de fray Gonzalo de Medina, prior que fue del convento } \\
\text { de San Isidoro del Campo, ya le habían dado antes otra ayuda. }\end{array}$ \\
\hline 1631 & $\begin{array}{l}\text { A petición que dio Constanza de León, madre enfermera, mandaron } 200 \text { reales de ayuda de costa para } \\
\text { casamiento de su hija. La anciana madre y a la hermana tullida de Agustín Alva que había sido } \\
\text { mayordomo y cura por } 25 \text { años en el hospital recibieron dos libras de pan blanco, dos libras de pan baso, } \\
3 / 4 \text { de carne de carnero, una libra de pescado fresco y } 1 / 4 \text { de salado durante todos los días de su vida. }\end{array}$ \\
\hline 1632 & $\begin{array}{l}\text { Isabel de Grimaldo, madre de fray Álvaro de Molina, cura del hospital, recibió } 150 \text { reales al año durante } \\
\text { toda su vida para su manutención y la de su hija. }\end{array}$ \\
\hline 1635 & $\begin{array}{l}\text { "A la pretensión y petición que dio Constanza de León madre enfermera que fue de este hospital en que } \\
\text { pide que atento a la mucho que sirvió en este hospital en diferentes oficios desde que sirvió siendo } \\
\text { doncella y a lo mucho que así mismo sirvió su marido y hoy por no poder más se ha ido del hospital y } \\
\text { está en compañía de una hija suya se le diese la ración que solía tener en este hospital siendo madre en } \\
\text { él y algún dinero para poder pagar sus necesidades. Mandaron y por una vez tan solamente se le den } 400 \\
\text { reales por vía de limosna y ayuda de costa". }\end{array}$ \\
\hline 1636 & $\begin{array}{l}\text { Constanza de León volvió a pedir ayuda de costa en 1636, pero esta vez se lo denegaron, pero } \\
\text { rectificaron los patronos en la junta particular siguiente atento a sus necesidades, mandaron que por vía } \\
\text { de limosna le diesen } 200 \text { reales por esta vez. }\end{array}$ \\
\hline 1637 & $\begin{array}{l}\text { La hermana de Álvaro de Molina, mayordomo y cura con más de } 25 \text { años de servicio se le dio } 3 \text { libras } \\
\text { de pan y } 3 / 4 \text { libras de carnero y } 150 \text { reales anuales por los servicios de su hermano por estar tullida de } \\
\text { pies y manos en una cama. }\end{array}$ \\
\hline 1638 & $\begin{array}{l}\text { En un memorial que dio Luisa de Salas, hija de Luis de Salas, boticario que fue del hospital por más de } \\
16 \text { años pidió se le diese alguna limosna por haberse quedado pobres. Se les concedió } 24 \text { reales como } \\
\text { limosna. }\end{array}$ \\
\hline 1639 & $\begin{array}{l}\text { Se le dio a Francisca Joffre de Loayza, de casi } 80 \text { años, hermana de d. Joffre administrador del hospital } \\
300 \text { reales de ayuda a sus necesidades del superávit de la renta de la obra pía de Diego de Yanguas por } \\
\text { los días de su vida. }\end{array}$ \\
\hline 1640 & Por vía de limosna a Beatriz de Castro viuda de don Francisco Fragoso, cirujano, que por ser pobre se \\
\hline
\end{tabular}




\begin{tabular}{|l|l|}
\hline & le nombre en una obra pía de Diego de Yanguas. \\
\hline 1641 & Ana López, viuda de Juan Merino, criado del hospital real y medio cada día. \\
\hline 1644 & La viuda de Alonso Román, sangrador, proveniente del fondo de convalecencia, recibió 100 reales. \\
\hline 1676 & $\begin{array}{l}\text { María Merino de García, esposa del cirujano, le entregaron } 30 \text { ducados anuales hasta su muerte. Le } \\
\text { quitaron la ayuda en 1688 debido a la crisis económica general de fines del XVII. }\end{array}$ \\
\hline 1682 & $\begin{array}{l}\text { Ana Domínguez, esposa del despensero, que trabajó 30 años, se le dio una ración diaria de pan, carne y } \\
\text { pescado. }\end{array}$ \\
\hline 1696 & $\begin{array}{l}\text { Clara Osorio, viuda del médico, recibió ayuda de costa anual de 200 reales de vellón. Ana Osorio, viuda } \\
\text { prestado por Andrés Osorio cirujano que fue del hospital. }\end{array}$ \\
\hline 1697 & $\begin{array}{l}\text { Jerónima Paula, hija del difunto despensero Juan Gómez, se le dio una ración de comida: carta de carne, } \\
\text { hogaza de pan y un aposento en el hospital para vivir. }\end{array}$ \\
\hline 1698 & $\begin{array}{l}\text { Luisa Pérez, hija de Juan Pérez, difunto boticario del hospital, se le asignó una habitación, pero sin ración } \\
\text { de comida. Esta ayuda cesaba si tomaba estado de casada. }\end{array}$ \\
\hline
\end{tabular}

Fuente: ADPS. Legajo 4B. Libro de juntas capitulares (1616-1637), f.80r (1631); Legajo 4B. Libro de actas capitulares, f.112 r (1635); Legajo 4B. Libro de actas capitulares, f.124 v (1636); Legajo 4B. Libro de actas capitulares (16591687), f.140 r (1676); Legajo 4B. Libro de actas capitulares (1659-1687), f.162 v (1681); Legajo 4B. Libro de actas capitulares (1659-1687), f.177 r (1682); Legajo 4B. Libro de actas capitulares (1687-1715), f.59 r (1696); Legajo 4B. Libro de actas capitulares (1687-1715), f.76 v (1697); Legajo 4B. Libro de actas capitulares (1687-1715), f.82 v (1698).

\subsection{Mujeres que pagaban para vivir en el hospital}

El hospital ofrecía gratuitamente "camas de incurables" a algunas de sus trabajadoras donde pasar los últimos días de sus vidas. El mantenimiento de estas camas era muy caro, así que algunas fueron obtenidas por mujeres que podían pagarlo, entregando sus casas al hospital bajo testamento o dinero en efectivo. Por ejemplo: a fines del siglo XVIII, en 1784, se dio una cama a Francisca Martínez, soltera, dando por ello la adjudicación de una casa: "Por otro memorial dado por doña Francisca Martínez de estado honesto $^{50}$. También, alguna mujer accedía a estas camas por recomendación de algún

\footnotetext{
${ }^{50}$ ADPS. Legajo 4B. Libro de actas capitulares (1764-1787), f.125 r (1783).
} 
personaje influyente que beneficiaba al hospital como un personaje de la nobleza, del cabildo o del alto clero.

Asimismo, en el periodo de 1658 a 1709, una madre mayor, Ana de Meneses, legó parte de sus ahorros y bienes a la protección de parientes femeninas. La matriarca de esta cadena de mujeres que se mantuvieron en el hospital por dos generaciones, había dejado un importante legado testamentario a favor del hospital de 2.400 ducados de principal con una renta de 120 ducados anual, sin embargo disminuyó tanto la renta por la crisis económica, que se ordenó la baja de las mandas y legados. Los mismos patronos del hospital dieron a Luisa de Meneses, una cama de incurables y ración en habitación aparte, siendo atendida por una sobrina. Posteriormente, en 1709, se le asignó una cama de incurables a Josepha Bonifacia Meneses sobrina nieta de Ana de Meneses, madre mayor que murió en 1658 que había estado viviendo en el hospital en un cuarto con una sobrina de la madre mayor hasta que murió ${ }^{51}$.

A partir de la segunda mitad del siglo XVIII, el acceso a una cama de incurables se hizo más monetario. En 1771, a solicitud de pretensión de una cama de incurables o de supernumeraria de Rosalía Fernández a cambio de una casa ${ }^{52}$, le concedieron una cama de incurables supernumeraria, cuando vacase alguna. Mientras que a Nicolasa Bravo no le consintieron por que ofreció dar sólo 100 pesos a razón de 4 cada mes hasta cumplir con la cantidad propuesta.

2.20. Las mujeres que pedían liberar cautivos de moros

El hospital y los dos patronazgos principales Diego de Yanguas y Juana Núñez Pérez dieron limosnas para liberar cautivos de moros, generalmente, en Argel y en Túnez. Los niños y los clérigos costaban más que los hombres y mujeres. Se mandaban peticiones

\footnotetext{
${ }^{51}$ ADPS. Legajo 4B. Libro de actas capitulares (1687-1715), f.185 r (1709).

${ }^{52}$ ADPS. Legajo 4B. Libro de actas capitulares (1764-1787), f.39 r (1770).
} 
de parte de mujeres para liberar a hijos y esposos. Por ejemplo: en 1635: Catalina Jiménez, viuda, pidió liberar a su hijo cautivo en Túnez de Turquía, dándosele 15 ducados. Ana de Campilllo pidió liberar a su esposo, cautivo en Argel, facilitándosele 10 ducados.

\subsection{Las rentistas o inquilinas}

Algunas mujeres que tenían a sus esposos ausentes en Indias o eran viudas solicitaban disminución de rentas de arrendamiento o aumentó de vidas de las casas que el hospital rentaba.

\subsection{Reclusas de la Inquisición}

Los hospitales solían ser lugares a donde eran enviadas reclusas de la Inquisición a purgar sus penas (Mas 2003: 30; Medina 1956: 301; López 2014: 256) ${ }^{53}$. Hospitales sevillanos a donde eran enviados reos era el hospital de las bubas, el Cardenal y otros (Gil 2000: 250-251). El hospital de las Cinco Llagas albergó a algunas de estas mujeres e incluso hombres. Por ejemplo: "El 29 de abril de 1636, Francisca de Santa Cruz, natural de Triana, mujer de Matías Alonso de la Fuente entró por reclusa en este hospital por mandado de los padre inquisidores por tiempo de un año desde este presente día" ${ }^{54}$. Otro caso es el de Micaela Meléndez de 60 años conocida como la hechicera, en 1717, fue

\footnotetext{
53 Una vez despojados de los sambenitos tras la celebración del auto los reos podían ser condenados a reclusión en distintos conventos y hospitales. Reas condenadas a azotes públicos y permanecer por varios años en los hospitales, como fue el caso de dos mujeres condenadas a diez años a servir en el hospital de la Caridad de Lima en 1749. También se ve un caso de una rea condenada a un año de reclusión en el hospital Divino Salvador, en México.

${ }^{54}$ ADPS. Legajo 242. Libros de entrada y salida de enfermas(1604-1648), 29/04/1636, f. 107 r; Legajo 4B. Libro de juntas o actas capitulares de patronos del Hospital de las Cinco Llagas (1659-1687), f. $63 \mathrm{r}$ (1665). Este hospital recibía reos de ambos sexos. Uno de ellos fue Andrés de los Cobos quien sirvió la plaza de enfermero de convalecencia masculina. Aunque estaba en depósito por el Santo Tribunal, el hospital le daba cien reales de limosna anual, pues no ganaba salario. La inquisición lo "depositó" como una manera de expiar alguna pena como enfermero de eclesiásticos en el Hospital de las Cinco Llagas.
} 
denunciada y llevada ante el Santo Oficio de Sevilla donde estuvo presa y fue más tarde llevada al Hospital de la Sangre para que cumpliese la penitencia de reclusión, impuesta por el tribunal. Indica que esta reo convenció al cirujano para que certificase su muerte y pudiese salir de su prisión (Torquemada 2000, 81-97) ${ }^{55}$.

\subsection{La gallinera y la botillera}

Las aves de corral eran esenciales en la dieta del hospital, al punto que se pagaban con gallinas una parte de las rentas de los alquileres de las distintas casas que tenía el hospital. Ya en 1546 existía el oficio de gallinera, ocupación que se hizo cargo la madre de llaves desde 1548, por lo que se le aumentó el salario. En 1569, volvió a aparecer la gallinera hasta 1582, cuando desapareció, volviéndose a ocupar de esta actividad la madre mayor. Desde 1682, el corral de gallinas pasó a responsabilidad de la madre portera.

El oficio de botillera duró muy poco en el hospital, creado con el fin de reducir el contacto del botiller con las mujeres de la clausura, pero sin éxito, pues tuvo una duración bastante discontinua desde 1584 a 1601. Su función fue controlar que el área femenina estuviese abastecida de lo necesario y avisar a la madre mayor de lo que faltase. Esta función la asumió la madre mayor al desaparecer la botillera. Nunca figuró en ninguna constitución del hospital. Este oficio realizada por una mujer fue reemplazada por un hombre, el botiller, desde 1603. Sin embargo, la botillera del área femenina continuó existiendo adosada como una obligación más de la madre mayor.

\section{Conclusiones}

El hospital de la Sangre de Sevilla albergaba mucha gente para llevar a cabo su trabajo diario, en especial se requería de importante número de mujeres más allá de la que

\footnotetext{
55 Información obtenida del Archivo Histórico Nacional. AHN. Inquisición, legajo 3736, exp. 141 y libro 668. Auto de la fe de la Inquisición de Sevilla de 1717.
} 
constaba en sus reglamentos y que salieron a la luz al examinar detalladamente la documentación primaria. Así, descubrimos que no sólo de enfermas y enfermeras estaba conformado el mundo femenino de este hospital, sino también por otras mujeres como beatas, donadas, esclavas, libertas, enfermeras "vagantes", amas de cría, comadres, inquilinas, huéspedes, madres y hermanas de religiosos, esposas e hijas de trabajadores laicos, familias de mujeres conformadas por viudas, hijas, sobrinas de ministros y criados que habían fallecido y se encontraban en calidad de "desamparadas" que el hospital acogía y amparaba. Todas estas mujeres no necesariamente vivían en el área femenina, sino en las distintas habitaciones que tenía el Hospital de la Sangre, conformando una verdadera casa de comunidad y clausura de mujeres tal cual era denominado asimismo según constitución.

Hay un mundo de féminas que pululaban el mundo hospitalero que no es conocido en la historiografía sobre hospitales. Un hospital grande como el de la Sangre de Sevilla tenía una pléyade de mujeres que vivían, trabajaban, permanente o temporalmente. Hay que tener en cuenta que un hospital de la Edad Moderna no sólo era para atender enfermas sino para proporcionar otros servicios a la población y a las autoridades como asistencia especial durante las pestes, alberge durante las inundaciones, reclusión y trabajo a las reclusas de la Inquisición, entrega de dotes matrimoniales por trabajo, amparo y asilo a incurables y ancianos, entrega de dinero para liberar cautivos de los moros, etc. También, hospedaba a los familiares femeninos de algunos trabajadores y muchas veces se hacía cargo de ellas al morir el trabajador. Este hospital tenía tanto prestigio al punto que algunas mujeres en el ocaso de sus vidas ofrecían sus casas a cambio de la atención, cuidado y bien morir en una cama en el hospital, no en calidad de enfermas sino de "incurables".

\section{Referencias Bibliográficas}

Beteta Martín, Yolanda. 2011. "De la Costilla de Adán a concubina del diablo. La demonización de los saberes y del cuerpo femenino en el Malleus Maleficarum". 
La Querella de las mujeres III. La Querella de las mujeres antecedente de la polémica feminista. Madrid: Almudayna: 45-73.

Mas Galvañ, Cayetano. 2003. "Un grupo de alumbrados en el sur valenciano durante el siglo XVII (Novelda y Alicante, 1679-1682)". Revista de Historia Moderna. Anales de la Universidad de Alicante, 21: 7-51.

Cabré I Pairet, Monserrat. 2005. "Como una madre, como una hija: las mujeres y los cuidados de salud en la Baja Edad Media". Historia de las mujeres en España y América Latina de la prehistoria a la Edad Media. Dir. Isabel Morant. Madrid: Ediciones Cátedra, vol. I. 637-657.

Campo Guinea, María del Juncal. 2004. "El matrimonio clandestino: procesos ante el Tribunal Eclesiástico en el Archivo Diocesano de Pamplona (siglos XVI-XVII)". Príncipe de Viana, Año nº 65, 231: 205-222.

Carmona García, Juan Ignacio. 1976. Una aportación a la demografía de Sevilla entre los siglos XVIII y XIX. Una aportación a la demografía de Sevilla en los siglos XVIII y XIX: Las series parroquiales de San Martín (1750-1860). Sevilla: Diputación Provincial de Sevilla.

. 1997. "Análisis histórico del hospital de las Cinco Llagas, de 1500 a 1837”. El Parlamento de Andalucía, Sevilla, Parlamento de Andalucía. Sevilla: Parlamento de Andalucía. 57-76.

Cuenca Toribio, José Manuel. 1976. Historia de Sevilla. Del Antiguo al Nuevo Régimen. Sevilla: Universidad de Sevilla.

Domínguez Ortiz, Antonio. 1992. "La Ciudad". La Sevilla de las Luces. Sevilla: Ayuntamiento de Sevilla.

Escalona Jiménez, Manuel. 1998. "Los donativos de la ciudad de Sevilla durante el reinado de Carlos II". Espacio, Tiempo y Forma. Serie IV.H. Moderna. t. 11. 281301.

Eseverri Chavarri, Cecilio. 1995. Historia de la enfermería española $e$ hispanoamericana. Madrid: Editorial Universitas.

Fuente Pérez, María Jesús. 2010. "Voces pro-femeninas en la Querella de las mujeres: Álvaro de Luna y El libro d las Claras y Virtuosas Mujeres". La Querella de las mujeres: Análisis de textos. Ed. Cristina Segura Graiño. Zaragoza: Asociación Cultural Al-Mudayna. 131-148.

García Martín, Pedro.2005.’La Odisea al Paraíso. La peregrinación a Jerusalén de Don Fadrique Enríquez de Ribera". Arbor CLXXX, 711-712, marzo-abril: 559-580.

Gil, Juan. 2000. Los conversos y la Inquisición sevillana, Vol 1. Sevilla: Fundación El Monte. 
Gómez García, María del Carmen. 1996. “Trabajo y actividades de las religiosas en los conventos malagueños (s. XVIII)". El trabajo de las mujeres: siglos XVI- XX. Eds. María Jesús Matilla y Margarita Ortega. Madrid: Universidad Autónoma de Madrid. 107-116.

Hernández Martín, Francisca. 1996. Historia de la enfermería en España: Desde la antigüedad hasta nuestros días. Madrid: Síntesis.

López Falante, Dolores y María de la Torre Liébana. 1995. "El Hospital de las Cinco Llagas de Sevilla: un modelo de organización de instituciones de beneficencia durante el Antiguo Régimen”. Archivo Hispalense. T. LXXVIII, 237 Sevilla. 6177.

López Ridaura, Cecilia. 2014. "La caza de brujas en la Nueva España: Monclova, Coahuila, 1748-1753”. EHumanista, 26: 234-263.

Matute y Gaviria, Justino.1982. Noticias relativas a la Historia de Sevilla que no constan en sus anales, recogidas de diversos impresos y manuscritos, [Imp. de E. Rasco, 1886]. Sevilla: Renacimiento.

Medina, José Toribio. 1956. Historia del tribunal de la Inquisición de Lima: 1569-1820. Santiago de Chile: Fondo Histórico y Bibliográfico José Toribio Medina, T.II.

Moreno Alonso, Manuel.2004. Historia de Andalucía. Sevilla: Ediciones Alfar.

Navagero, Andrés. 1983. Viaje por España (1524-1526). Madrid: Ediciones Turner.

Perry, Mary Elizabeth. 1990. Gender and disorder in early modern Sevilla. Princeton NJ: Princeton University Press.

.1996. "Las mujeres y su trabajo curativo en Sevilla, los siglos XVI y XVII", El trabajo de las mujeres: siglos XVI- XX. Eds. María Jesús Matilla y Margarita Ortega. Madrid: Universidad Autónoma de Madrid: 57-70.

Ramos Carrillo, Antonio. 2003. La sanidad sevillana en el siglo XIX: El hospital de las Cinco Llagas. Sevilla: Diputación Provincial de Sevilla.

Rivasplata Varillas, Paula Ermila. 2011. Doncellas de dote del Hospital de las Cinco Llagas de Sevilla. Una lectura en clave de género. Berlín: Editorial Académica Española.

2012. Aproximación histórica de la enfermería femenina en Europa y América. La enfermería en el hospital de las Cinco Llagas de Sevilla y los hospitales de Lima en el XVIII y parte del XIX. Berlín: Editorial Académica Española.

2014. "La madre mayor del Hospital de las Cinco Llagas de Sevilla en el Antiguo Régimen”. Hispania Sacra, LXVI, 134, julio-diciembre: 529-574. 
Segura Graiño, Cristina. 2011. "Las razones por las que los hombres deben valorar a las mujeres. La Cárcel de amor de Diego de San Pedro". La Querella de las mujeres III. La Querella de las mujeres antecedente de la polémica feminista. Madrid: Almudayna: 125-139.

Torquemada Sánchez, María Jesús. 2000. La Inquisición y el diablo: supersticiones en el siglo XVIII. Sevilla: Universidad de Sevilla. 